Ciência \& Tecnologia dos Materiais 29 (2017) e224-e228

http://ees.elsevier.com/ctmat

Special Issue "Materiais 2015"

\title{
Adsorption of MCPA, 2,4-D and diuron onto activated carbons from wood composites
}

\author{
I.P.P. Cansado a, " , P.A.M. Mourão ${ }^{\text {a }}$ J.A.F.L. Gomes ${ }^{\mathrm{a}}$, V. Almodôvar ${ }^{\mathrm{a}}$ \\ ${ }^{a}$ Departamento de Química, Centro de Química de Évora, Instituto de Investigação e Formação Avançada, Escola de Ciências e Tecnologia, \\ Universidade de Évora - Rua Romão Ramalho, 59, 7000-671 Évora, Portugal
}

\begin{abstract}
Activated carbon adsorbents were produced from particleboard and medium-density fiberboard, industry originated wastes, without value added applications. These materials were characterized, showing a well-developed microporous structure reaching $0.58 \mathrm{~cm}^{3} / \mathrm{g}$, and afterwards, their potential application for the removal of phenoxy acetic acids and substituted urea herbicide was evaluated. Studies in liquid phase were conducted in 2,4-dichlorophenoxy acetic acid (2,4-D), 4-chloro-2-methylphenoxy acetic acid (MCPA) and 3-(3,4-dichlorophenyl)-1,1-dimethylurea (diuron), being the obtained data linearized using the Langmuir and Freundlich equations. Results indicated high removal capabilities for the adsorptives in study, reaching 0.97 , 1.37 and $1.87 \mathrm{mmol} / \mathrm{g}$ for diuron, 2,4-D, and MCPA respectively, allowing the conclusion that these materials should be studied further, having in mind real life applications.
\end{abstract}

(C) 2017 Portuguese Society of Materials (SPM). Published by Elsevier España, S.L.U. All rights reserved.

Keywords: Activated carbon; adsorption; pesticides; monolith wood.

\section{Introduction}

Increasing use of pesticides, in agriculture and domestic activities for pest control is polluting our water resources, gradually forming a strong class of water pollutants, which is really a great concern, according to the World Health Organization and United States Environment Protection Agency [1,2].

Pesticides are also used in different purposes and they may be classified according to their function, chemical groups or even also to their nature, as organic or synthetic [3].

Several methods are described for pesticide removal such as ozonation, photocatalytic or aerobic degradation, combined photo-Fenton and biological

\footnotetext{
* Corresponding author.

E-mail address: ippc@uevora.pt (I.P.P. Cansado)
}

oxidation, oxidation processes, filtration, coagulation, sedimentation and different adsorption systems.

Adsorption is considered an attractive method for removing pollutants and in particular pesticides from dilute solutions which involve the previous determination of the adsorptive behaviour on various adsorbents. Activated carbon (AC) materials have an important place among the adsorbents tested as they can be prepared from a wide variety of relatively low cost, natural or synthetic precursors, as largely described in the literature, and their improved properties allow them to adsorb various organic and inorganic compounds for a long time, being able to be regenerated and reused for several times [4-11].

The industries are still looking for environmentally friendly and cheaper AC retaining or increasing the adsorption capacities when compared with those often used for the same purpose. The use of agricultural or industrial by-products to produce high value $\mathrm{AC}$ can be the way to follow in order to increase the adsorbents efficiency and also reduce its final cost. 
The purpose of this work was to evaluate the adsorption potential of $\mathrm{AC}$, prepared from the particleboard (PB) and medium-density fibreboard (MDF) monoliths, which are waste from the wood industries, for removal of selective herbicides, such 2,4-dichlorophenoxy acetic acid (2,4-D), 4-chloro-2methylphenoxy acetic acid (MCPA), which are phenoxy acetic acids and 3-(3,4-dichlorophenyl)-1,1dimethylurea (diuron), which is a substituted urea herbicide, from the liquid phase. These pesticides were chosen since they present very different chemical and physical properties (Table 1) and could thereby be expected to give additional information on the adsorptive properties of the AC tested.

\section{Experimental Procedure}

2.1. Activated carbon preparation and characterization

A series of $\mathrm{AC}$ was produced, from MDF and $\mathrm{PB}$ monoliths, by physical activation with carbon dioxide. First, the monolith was submitted to a heating rate of $2 \mathrm{~K} / \mathrm{min}$, followed by a dwell time of $60 \mathrm{~min}$, at $383 \mathrm{~K}$; the second heating step was at $10 \mathrm{~K} / \mathrm{min}$ until $1073 \mathrm{~K}$, followed by a dwell time of $30 \mathrm{~min}$, under a $\mathrm{N}_{2}$ gas flow. The physical activation was carried out at $1073 \mathrm{~K}$ under a $\mathrm{CO}_{2}$ flow and different dwell times were used in order to achieve a large range of burnoffs, ranging from 11 to $87 \mathrm{wt} . \%$.

A complete characterization of the $\mathrm{AC}$ was achieved through different methods, normally used for this purpose, such as $\mathrm{N}_{2}$ adsorption at $77 \mathrm{~K}$, CHNS-O elemental analysis, point of zero charge and thermogravimetrical analysis of the precursors. The detailed description of the experimental procedure is given elsewhere $[4,7,8]$.

\subsection{Pesticides removal from liquid phase}

Between the series of $\mathrm{AC}$, those presenting a wider mean pore size and highest pore volume were selected, for MCPA, 2,4-D and diuron removal from the liquid phase. All pesticides used were obtained from Sigma-Aldrich, with purity ranging from 95.0 to 99.9\%.

Previous studies on the influence of $\mathrm{pH}$ of the medium and contact time were performed in order to determine the ideal adsorption conditions for each pesticide [7]. The adsorption of different pesticides was carried out in a batch assays. A fixed quantity of $\mathrm{AC}$ was added to $25 \mathrm{~mL}$ of aqueous solutions of known concentrations of each pesticide, then the Erlenmeyer flasks were hermetically closed and placed in agitation for an equilibrium time, at $298 \mathrm{~K}$.
The suspension was then filtered, and the residual pesticides were determined by UV/visible spectrophotometry, using a Thermo Nicolet Evolution 300 UV-VIS, at the appropriate wavelength. The amount of pesticides adsorbed on the AC was calculated by difference between the initial and the equilibrium concentrations.

Table 1. Pesticides physical properties.

\begin{tabular}{|c|c|c|c|}
\hline & \multicolumn{3}{|l|}{ Adsorptive } \\
\hline & MCPA & $2,4-\mathrm{D}$ & Diuron \\
\hline $\begin{array}{l}\text { Molecular weight } \\
(\mathrm{g} / \mathrm{mol})\end{array}$ & 200.62 & 221.04 & 233.09 \\
\hline Molecular form & $\mathrm{C}_{9} \mathrm{H}_{9} \mathrm{ClO}_{3}$ & $\mathrm{C}_{8} \mathrm{H}_{6} \mathrm{Cl}_{2} \mathrm{O}_{3}$ & $\mathrm{C}_{9} \mathrm{H}_{10} \mathrm{Cl}_{2} \mathrm{~N}_{2} \mathrm{O}$ \\
\hline $\begin{array}{l}\text { Water solubility } \\
\mathrm{T}=293 \mathrm{~K}(\mathrm{mg} / \mathrm{L})\end{array}$ & 825 & 900 & 42 \\
\hline
\end{tabular}

\section{Results and Discussion}

\subsection{Textural and chemical characterization}

In this work, the MDF and PB monoliths were used as precursor, resulting in $\mathrm{AC}$ samples that retain the initial shape, which is an important characteristic for industrial applications [10], especially in continuous flow systems for liquid phase adsorption. All AC from the series were textural characterized by $\mathrm{N}_{2}$ adsorption at $77 \mathrm{~K}$ and the obtained isotherms were essentially of type I, agreeing to a microporous structure. The isotherms were analysed based on BET, DR and $\alpha_{\mathrm{s}}$ methods and the textural parameters are presented in Table 2 .

Table 2. Textural parameters of activated carbons.

\begin{tabular}{llllll}
\hline $\begin{array}{l}\text { Activated } \\
\text { carbon }\end{array}$ & $\begin{array}{l}\mathrm{A}_{\mathrm{BET}} \\
\left(\mathrm{m}^{2} / \mathrm{g}\right)\end{array}$ & $\begin{array}{l}\mathrm{A}_{\mathrm{S}} \\
\left(\mathrm{m}^{2} / \mathrm{g}\right)\end{array}$ & $\begin{array}{l}\mathrm{V}_{\mathrm{S}} \\
\left(\mathrm{cm}^{3} / \mathrm{g}\right)\end{array}$ & $\begin{array}{l}\mathrm{V}_{0} \\
\left(\mathrm{~cm}^{3} / \mathrm{g}\right)\end{array}$ & $\begin{array}{l}\mathrm{L}_{0} \\
(\mathrm{~nm})\end{array}$ \\
\hline MDF 5950 & 1195 & 19.7 & 0.48 & 0.47 & 1.02 \\
MDF 5933 & 805 & 14.3 & 0.33 & 0.31 & 0.66 \\
PB 5960 & 1211 & 15.7 & 0.58 & 0.49 & 1.15 \\
PB 5936 & 926 & 11.8 & 0.38 & 0.37 & 0.80 \\
\hline
\end{tabular}

$\mathrm{A}=$ surface area, $\mathrm{V}=$ pore volume, $\mathrm{L}=$ mean pore width. The $\mathrm{BET}$, $\mathrm{S}$ and 0 subscripts correspond to BET, $\alpha_{\mathrm{S}}$ and DR methods, respectively.

The sample PB 5960 and MDF 5950, and PB 5936 and MDF 5933 were prepared through the same activation time, 240 and $120 \mathrm{~min}$ respectively. It is evident that micropore volume and mean pore size increase with the activation time. Moreover, when using the same experimental conditions, the $\mathrm{AC}$ prepared from $\mathrm{PB}$ show a higher micropore volume, when comparing with MDF, reaching $0.58 \mathrm{~cm}^{3} / \mathrm{g}$ and 
wider mean pore size, highlighting the effect of the macroscopic characteristics of the precursors.

In the series, the $\mathrm{AC}$ presented a high carbon content ranging from 66.7 to $72.6 \%$ and a nitrogen content varying from 2.5 to $3.8 \%$. The AC prepared from MDF present the highest nitrogen content $(>3.5 \%)$ and a high oxygen content, ranging from 8.7 to $12.5 \%$, inducing a basic character on the $\mathrm{AC}$, noticeable on the point of the zero charge, as the four AC chooses exhibited a pzc $>10$. Based on their textural and chemical characteristics, the PB 5960, PB 5936, MDF 5950 and MDF 5933 were selected for application on pesticides removal from the liquid phase.

\subsection{Pesticides removal from liquid phase}

The adsorption of MCPA, 2,4-D and diuron as a function of contact time was first evaluated and an example of these data is shown in Fig. 1.

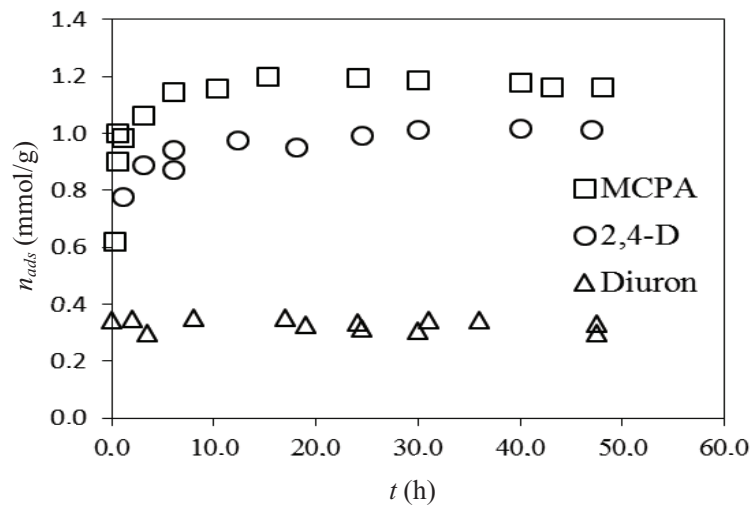

Fig. 1. Adsorption kinetics of MCPA, 2,4-D and diuron.
As it can be observed, the adsorption kinetics have similar trends and the pesticides adsorption can reach more than $80 \%$ in the initial $2.5 \mathrm{~h}$ and apparent equilibrium is reached within $24 \mathrm{~h}$. The residual pesticides were evaluated at an adequate wavelength such: 228.6 or $279.0 \mathrm{~nm}$ for MCPA, 230 or $284 \mathrm{~nm}$ for 2,4-D and 212 or $250 \mathrm{~nm}$ for diuron. The pesticides adsorption isotherms were acquired at optimal conditions ( $\mathrm{pH}=3.0$ for MCPA and 2,4-D and $\mathrm{pH}=7.0$ for diuron) and the data for the MCPA adsorption on the four AC are illustrated in Fig. 2.

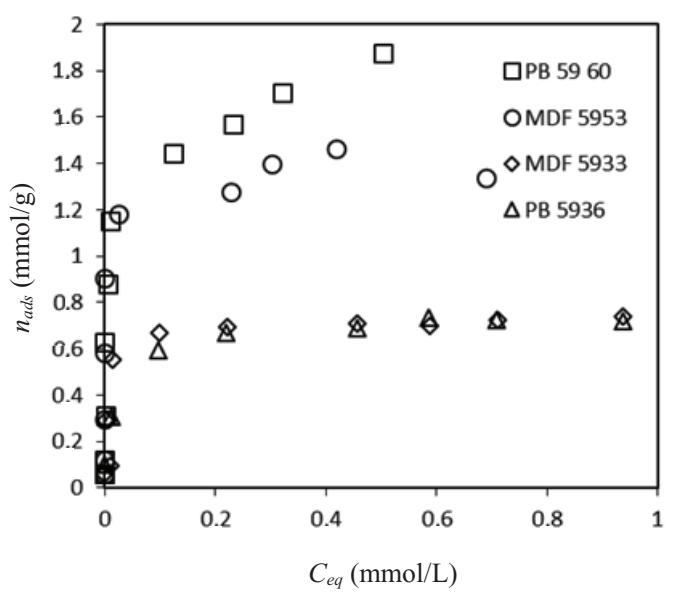

Fig. 2. Adsorption isotherms of MCPA from aqueous solutions, obtained at $298 \mathrm{~K}$, on AC prepared from MDF and PB, by physical activation with $\mathrm{CO}_{2}$.

From the isotherms and the data show in Table 3, it is clear that the adsorbed quantities of MCPA, 2,4-D and diuron increase along the sample sequence MDF 5933 $<$ PB $5936<$ MDF 5950 and PB 5960.

Table 3. Adsorption isotherm parameters of MCPA, 2,4-D and diuron onto AC prepared from MDF and PB.

\begin{tabular}{|c|c|c|c|c|c|c|}
\hline & System & $\begin{array}{l}n_{\max } \\
(\mathrm{mmol} / \mathrm{g})\end{array}$ & $\begin{array}{l}n_{m L} \\
(\mathrm{mmol} / \mathrm{g})\end{array}$ & $\begin{array}{l}K_{L} \\
\left(\mathrm{dm}^{3} / \mathrm{mmol}\right)\end{array}$ & $K_{F}(\mathrm{mmol} / \mathrm{g})\left(\mathrm{dm}^{3} / \mathrm{mmol}\right)_{F}^{1 / n}$ & $n_{F}$ \\
\hline \multirow{4}{*}{ MCPA } & MDF 5950 & 1.46 & 1.44 & 188.6 & 1.54 & 13.90 \\
\hline & MDF 5933 & 0.73 & 0.72 & 185.6 & 0.74 & 23.20 \\
\hline & PB 5960 & 1.87 & 1.68 & 165.9 & 1.99 & 7.10 \\
\hline & PB 5936 & 0.78 & 0.73 & 161.2 & 0.74 & 20.50 \\
\hline \multirow{4}{*}{$2,4-\mathrm{D}$} & MDF 5950 & 1.19 & 1.18 & 55.1 & 1.34 & 5.60 \\
\hline & MDF 5933 & 0.71 & 0.72 & 42.5 & 0.72 & 12.10 \\
\hline & PB 5960 & 1.37 & 1.40 & 65.2 & 1.48 & 10.90 \\
\hline & PB 5936 & 1.11 & 1.09 & 60.6 & 1.12 & 10.40 \\
\hline \multirow{3}{*}{ Diuron } & MDF 5950 & 0.88 & 0.91 & 232.9 & 1.20 & 7.64 \\
\hline & PB 5960 & 0.97 & 1.03 & 158.7 & 4.53 & 1.93 \\
\hline & PB 5936 & 0.35 & 0.38 & 203.6 & 0.38 & 27.80 \\
\hline
\end{tabular}

$n_{\max }$ - maximum adsorption from the isotherm; $n_{m L}$ - monolayer capacity; $K_{L}$ - Langmuir constant; $K_{F}$ and $n_{F}$ - constant and exponent of Freundlich 
This sequence follows the same order as the surface area and the micropore volume of the adsorbent. The pesticides adsorbed follow the same order on each $\mathrm{AC}$, it means diuron $<2,4-\mathrm{D}<\mathrm{MCPA}$.

Taking into account the optimal $\mathrm{pH}$ of the adsorption medium and the basic nature of the adsorbents, it is understandable that MCPA and 2,4-D, presenting an acid nature, adsorbed more when compared with diuron. However, the lesser adsorption of diuron could also be attributed to its greatest molecular dimension and to its very low water solubility when compared with MCPA and 2,4-D. It means, in diluted solutions, the diuron molecules are too far from the $\mathrm{AC}$ surface and the external transport can be considered as the limiting step in the process.

The most widely used equations for modelling equilibrium data, from experimental liquid phase adsorption, are Langmuir and Freundlich equations.

The Langmuir equation presents some limitations, especially when the adsorption is not limited to a monolayer and the adsorbent surface is heterogeneous. On the other hand, the Freundlich equation provides a very acceptable description of non-linear adsorption isotherms and the applicability of this equation for systems involving heterogeneous surfaces are further recommended.

\subsection{Langmuir adsorption isotherms}

The Langmuir equation could be expressed as follow:

$$
\frac{C_{e q}}{n_{a d s}}=\frac{1}{n_{m L} K_{L}}+\frac{1}{n_{m L}} C_{e q}
$$

where $n_{\text {ads }}$ is the measured adsorption at a solute equilibrium concentration $C_{e q}, n_{m L}$ the monolayer capacity and $K_{L}$ the Langmuir constant.

By plotting $\left(C_{e q} / n_{a d s}\right)$ versus $C_{e q}$, as illustrated in Fig. 3, the parameters $n_{m L}$ and $K_{L}$ could be obtained, as included in Table 3. With all combinations of pesticides/AC, the Langmuir equation fits very well with the experimental data and, in particular, a very good fit was found for system AC/MCPA.

For all systems, the values of $n_{m L}$ agree well with the respectively maximum value adsorbed, obtained directly from the experimental data. Moreover, the $K_{L}$ value, assessed for each pesticide, is relatively constant on the four AC tested.

\subsection{Freundlich adsorption isotherms}

The Freundlich equation can be described as follow:

$$
\log n_{a d s}=\log K_{F}+\frac{1}{n_{F}} \log C_{e q}
$$

$K_{F}$ and $n_{F}$ are parameters characteristic of the sorbentsorbate system, which must be determined by data fitting and whereas linear regression is generally used to determine the parameters of kinetic and isotherm models.

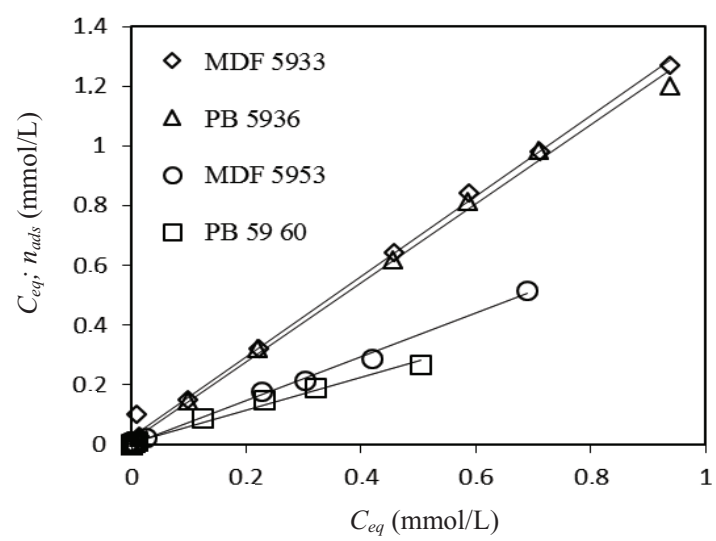

Fig. 3. Langmuir linearization for the adsorption isotherm of MCPA, from aqueous solutions, obtained at $298 \mathrm{~K}$, on activated carbons prepared from MDF and $\mathrm{PB}$.

Concerning the MCPA adsorption, and based on Fig. 4, the PB 5960 exhibits a lower $n_{F}$ value, which is in agreement with the more rounded isotherm shape as showed in Fig. 2.

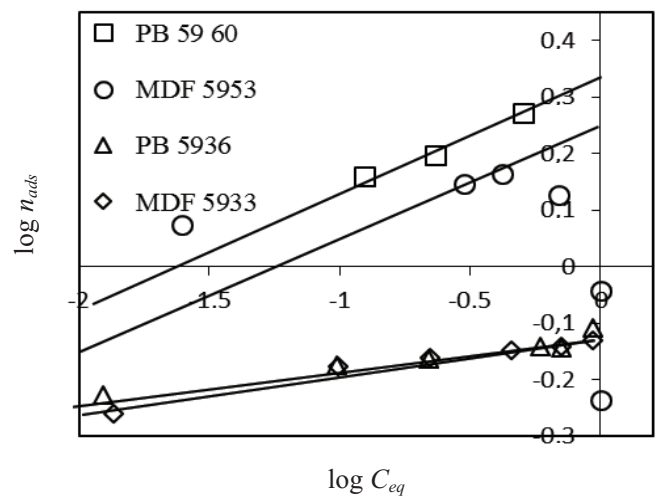

Fig. 4. Freundlich linearization for the adsorption of MCPA, from aqueous solutions, obtained at $298 \mathrm{~K}$, on activated carbons prepared from MDF and $\mathrm{PB}$.

The Langmuir linearization, for 2,4-D and diuron, not shown here, fits very well the experimental data and the $n_{m L}$ obtained are really close to the maximum quantity adsorbed. With these pesticides, the Freundlich linearization was less applicable.

The AC prepared from MDF or PB by physical activation with $\mathrm{CO}_{2}$, in particular the MDF 5960 and PB 5953, demonstrated high removal capacities for the three pesticides tested. For these systems, the amount adsorbed reaches almost the values found in 
the literature when AC commercial was used. For example, the best results found, with the commercial AC Filtrasorb 400, were 1.94 and $1.86 \mathrm{mmol} / \mathrm{g}$ of MCPA and 2,4-D, respectively [12]. Also the commercial AC darco G-60 removed $1.29 \mathrm{mmol} / \mathrm{g}$ of diuron [12].

The AC prepared from PB and MDF and tested on the MCPA, 2,4-D and diuron presented adsorption capacities for these pesticides very close to those obtained with the commercial one, which allow us to state that PB and MDF AC could be a great substitute of those most commonly used for this purpose.

\section{Conclusions}

A series of activated carbon was produced from the particleboard and medium-density fibreboard monoliths by physical activation, with carbon dioxide, at $1073 \mathrm{~K}$. A full characterization of the AC produced was achieved by nitrogen adsorption at $77 \mathrm{~K}$, elemental analysis, and point of zero charge. The AC retains the initial shape, presenting a very well developed microporous structure, a high oxygen content and a basic character, these being determinant characteristics for possible applications in the removal of pesticides from the liquid phase. The AC adsorption potential, for phenoxy acetic acids removal, such 2,4-D, MCPA and diuron, from the liquid phase was evaluated. The PB 5960, having a larger specific area, higher micropore volume and a wider mean pore size showed a higher adsorption capacity for the three pesticides tested. With all AC, the extent of the adsorption was found as diuron $<2,4-\mathrm{D}<\mathrm{MCPA}$ and was attributed to the different chemical composition, molecular size and water solubility of the pesticides. However, the four AC revealed a good performance for pesticides removal, similar to that achieved with the commercial AC used for this purpose, indicating that these materials can be seen as an added value product with the capability to take its place along with the traditional adsorbents.

\section{Acknowledgements}

This work was supported with national funds through Fundação para a Ciência e Tecnologia (FCT, Portugal) and co-financed by Fundo Europeu de Desenvolvimento Regional (FEDER) trough Programa COMPETE - Programa Operacional Fatores de Competitividade (POFC), in the scope of the projects EXPL/AAG-REC/1181/2013 (FCOMP01-0124-FEDER-041551) and Pest-OE/QUI/UI0619/ 2014.

Authors furthermore thank to SONAEINDUSTRIA for the supply of the wood composite and to J.M.A. Figueira (Assistente Operacional, Physics Dep.) in the adaptation works in the $\mathrm{AC}$ production furnace.

\section{References}

[1] Report of World Health Organization, Water Quality and Health Strategy 2013-2020,

$<$ http://www.who.int/water_sanitation_health/publications/2 013/water_quality_strategy.pdf $>$, (accessed 12.04.2015).

[2] United States Environment Protection Agency, Technical support document for water quality based toxics control, Tech. Rep. EPA/ 440/485032, DC, USA, 1985.

[3] The WHO Recommended Classification of Pesticides by Hazard and Guidelines to Classification, http://www.who.int/ipcs/publications/pesticides_hazard_200 9.pdf $>$, 2009, (accessed 12.04.2015).

[4] I.P.P. Cansado, P.A.M. Mourão, A.I. Falcão, M.M.L. Ribeiro Carrott, P.J.M. Carrott, Fuel Process. Technol. 103 (2012) 64.

[5] M. Mahramanlioglu, I. Kizilcikli, I.O. Biçer. M. Tuncay, J. Environ. Sci. Health, Part B - Pesticides B38(6) (2003) 813.

[6] M.A. Fontecha-Camara, M.V. Lopez-Ramon, L.M. Pastrana-Martınez, C. Moreno-Castilla, J. Hazard. Mater. 156 (2008) 472.

[7] I.P.P. Cansado, P.A.M. Mourão, M.M.L. Ribeiro Carrott, P.J.M. Carrott, Adv. Mater. Res. 107 (2010) 1.

[8] I.P.P. Cansado, P.C. Galacho, A.S. Nunes, M.M.L.R. Carrott, P.J.M. Carrott, Adsorpt. Sci. Technol. 28 (2010) 807.

[9] J.M. Salman, B.H. Hameed, Desalination 256 (2010) 129.

[10] E. Ayranci, Nu. Hoda, J. Hazard. Mater. B112 (2004) 163.

[11] A.K. Kercher, D.C. Nagle, Carbon 41 (2003) 3.

[12] K.Y. Foo, B.H. Hameed, J. Hazard. Mater. 175 (2010) 1. 